\title{
Research on hot stamping for a typical part of B1500HS boron steel using experiment and numerical simulation methods
}

\author{
Huiping $\mathrm{Li}^{1, a}$, Bingtao Tang ${ }^{2, a}$, Lianfang $\mathrm{He}^{1}$ and Cheng Wang ${ }^{1}$ \\ ${ }^{1}$ School of Materials Science and Engineering, Shandong University of Science and Technology, Qingdao 266590, PR China \\ ${ }^{2}$ School of Materials Science and Engineering, Shandong Jianzhu University, Jinan, PR China
}

\begin{abstract}
In the paper, a typical part of B1500HS boron steel was formed using the hot stamping tools, and the effect of austenitization temperature on the microstructure and mechanical properties of B1500HS steel was studied by the experiment and finite element methods. The results show that, the temperature of steel plate has a significant effect on the temperature of hot stamping tools, and the temperature of punch rises at a faster speed than that of die in the hot stamping process. The austenitization temperature and time both have significant effects on the size of martensite, but have not obvious effects on the hardness. The cooling rate of steel plate has a significant effect on the tensile strength when the austenitization temperature is $870{ }^{\circ} \mathrm{C}$. The fracture of sample austenitized at $870{ }^{\circ} \mathrm{C}$ or $900^{\circ} \mathrm{C}$ is the dimple, the fracture of sample austenitized at $930^{\circ} \mathrm{C}$ or $960^{\circ} \mathrm{C}$ is the mixture of quasicleavage and dimple. Key words: Hot stamping, Austenitization temperature, Microstructure, Mechanical properties.
\end{abstract}

\section{Introduction}

In order to reduce vehicle weight and tail-gas emission without compromising crash performance, most of automotive manufacturers focus upon application of new materials besides optimizing framework of vehicle. Body-in-white or BIW, in which a car body's sheet metal components have been welded together, is the largest structure of vehicle, and main contributor to the vehicle weight, so it is one of the best objectives of weight reduction. Mechanical performance of BIW can be improved with the weight reduction by using advanced high-strength steel (AHSS) or ultra high-strength steel (UHSS). But formability of AHSS or UHSS reduces remarkably with the enhancement of strength, and some defects, such as poor forming quality, cracking and spring-back, are easy to appear in the cold stamping.

At present, lots of research about the hot stamping of quenchable boron steel has been done in the world, such as the investigation of high-strength steel forming technology, design of hot stamping tools with cooling system, constitutive relationships of boron steel at high temperature, formability of quenchable boron steel in the hot stamping and so on. Kolleck et al. [1] studied the induction heating of boron steel in the hot stamping. The grade of austenitization as well as the mechanical properties of the quenched component had been taken into account in the research. This heating method can reduce the heating time, the investment costs and the floor space of heating device. Min et al. [2] presented a prediction model for hot forming limits of steel 22MnB5 based on Storen and Rice's Vertex theory and Logan-
Hosford yield criterion. By comparison, the calculated FLD based on the Vertex theory and four-order LoganHosford yield criterion was in good accordance with the measured FLD. Nikravesh et al. [3] described the effect of hot plastic deformation and cooling rate on the final properties of 22MnB5 steel in hot deformation process by means of deformation dilatometer. Li et al. [4] described the hot deformation behavior of B1500HS steel with the microstructure of austenite, ferrite + pearlite, bainite or martensite using the modified Arrhenius and Johnson Cook models. Mori [5], Yanagimoto [6], Khan [7] and et al. studied the bending spring-back of UHSS by experiment. Lim [8] and Xu [9] studied the cooling system design in the hot stamping die.

At present, many researchers have focused their emphasis on the study of numerical simulation of hot stamping process. Tekkaya et al. [10] presented the thermo-mechanical coupled simulation of hot stamping process by means of experimentally calculated material data and described a number of procedures for the simulation of hot stamping, aiming at a notable decrease in computation time. So et al. [11] studied the warm blanking and cold blanking of $22 \mathrm{MnB} 5$ steel, and compared the results of experiment and finite element simulation. Some recommendations for the manufacturer of 22MnB5 steel products were presented. Xing et al. [12] built a material model for the hot stamping of quenchable boron steel according to the experimental data of mechanics and thermal physical properties. The numerical simulation of hot stamping was done by ABAQUS software. The simulation results were basically in agreement with the experimental results. Lei et al. [13]

\footnotetext{
a Corresponding author: lihuiping99@163.com; tangbingtao@gmail.com
} 
simulated the cooling process of hot-stamping dies by CFX software, and studied the effect of processing parameters, such as pressure holding time and cooling water velocity, on the temperature of hot-stamping dies. The numerical simulation results had a good agreement with the experimental results. Bao et al. [14] studied the differences of effective quenching and forming precision between heat free bending and thermal contact bending by ABAQUS software. Liu et al. $[15,16]$ researched the hot stamping of $22 \mathrm{MnB} 5$ using the simulation and experiment methods. Bok et al. [17] studied the forming process of $\mathrm{B}$ pillar, and the data from simulation and experiment could provide some important information about the temperature, martensite distribution and technological parameters for the design of hot stamping. Cai et al. [18] studied the distributions of metallography, hardness and yield stress of 22MnB5 in the hot stamping process by using Ansys/Ls-Dyna and KirkaldyVenugopalan austenitic decomposition model.

In this paper, the effect of austenitization temperature on the microstructure and mechanical properties of B1500HS boron steel is studied by the experiment and finite element methods.

\section{Experiments}

\subsection{Materials}

The material used in the paper is B1500HS boron steel sheet with $1.6 \mathrm{~mm}$ thickness and non-coating. Microstructure of boron steel is about $25 \%$ pearlite and $75 \%$ ferrite, the yield strength and tensile strength are about $340 \mathrm{MPa}$ and $500 \mathrm{MPa}$. The chemical compositions of B1500HS are listed in Table 1. The size of steel blank used in the experiment is about $115 \times 115 \mathrm{~mm}$. The samples which are used to test the microstructure and mechanical performance are cut from the region I, II and III of stamped parts by the wire electric discharge machine (WEDM), as shown in Figure 1.

Table 1. Chemical composition of B1500HS (wt \%)

\begin{tabular}{|c|c|c|c|c|c|c|c|c|}
\hline $\mathrm{C}$ & $\mathrm{Si}$ & $\mathrm{Mn}$ & $\mathrm{S}$ & $\mathrm{P}$ & $\mathrm{Cr}$ & $\mathrm{Mo}$ & $\mathrm{Ti}$ & $\mathrm{B}$ \\
\hline 0.23 & 0.25 & 1.35 & 0.006 & 0.015 & 0.19 & 0.04 & 0.03 & 0.003 \\
\hline & & \multicolumn{1}{|c|}{} & & & & & & \\
\hline
\end{tabular}

(a) Hot stamped part

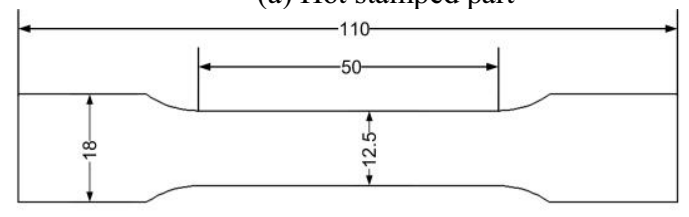

(b) Tensile sample

Figure 1. Schematic diagrams of part and sample (unit: $\mathrm{mm}$ )

\subsection{Quenching experiments}

Hot stamping tools used in the experiment are shown in Figure 2. The thermocouple positions are marked as symbol (1) (2) (3)and (4.) The material of tools is H13 steel. NiCr-NiSi thermocouples with the diameter of 2 $\mathrm{mm}$ and length of $100 \mathrm{~mm}$ are used to measure the temperature of tools. Data acquisition system TC-08 is used to convert the signal from thermocouples. Testing machine CMT5000 and other equipments are used to measure the hardness, tensile strength and microstructure of samples.

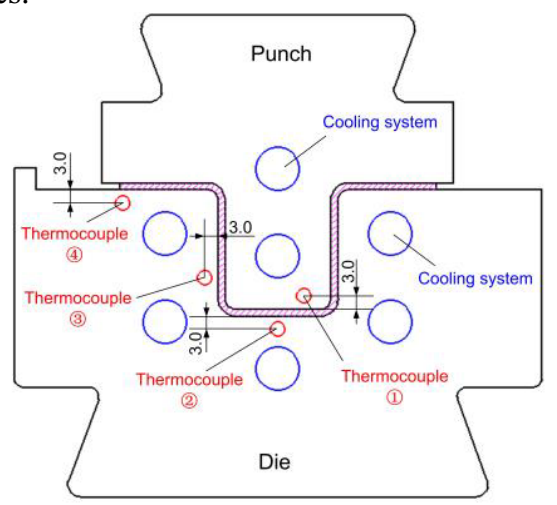

Figure 2. Schematic diagram of hot stamping tools

The temperature of resistance furnace is set to $870^{\circ} \mathrm{C}$. When the temperature arrives at about $870^{\circ} \mathrm{C}$, five steel plates are put into the furnace for austenitization. After heated for about $5 \mathrm{~min}$, the first steel plate is quickly transferred into the hot stamping tools, formed and cooled in the tools, and then moved out of the tools. Other four steel plates also undergo these steps in order. So the heating times of five steel plates are respectively about 300 s, 420 s, 540 s, $660 \mathrm{~s}$ and 780 s. For the hot stamping of steel plates at the austenitization temperature of $900{ }^{\circ} \mathrm{C}, 930{ }^{\circ} \mathrm{C}$ and $960{ }^{\circ} \mathrm{C}$, the operation steps are same as that at $870{ }^{\circ} \mathrm{C}$.

\section{EXPERIMENT RESULTS AND DISCUSSIONS}

\subsection{Temperature of completely austenitization}

The expansion curve attained by the quenching and deformation dilatometer DIL $805 \mathrm{~A} / \mathrm{D}$ shows that, the temperature (Ac1) at which pearlite transforms into austenite is about $725^{\circ} \mathrm{C}$, and the temperature (Ac3) at which ferrite transforms into austenite is about $810^{\circ} \mathrm{C}$, when the heating rate is about $200 / \mathrm{h}$.

The heating rate of steel plates in the heating furnace SX2-4-10G is much higher than $200{ }^{\circ} \mathrm{C} / \mathrm{h}$, and the heating rate has a significant effect on the temperature Ac1 and Ac3 [19]. In order to know the temperature curve of steel plate in the heating and cooling, a thermocouple is welded on the side middle of steel plate. The position of thermocouple is shown in Figure 3.

The temperature curve can be divided into six stages: 1 - heating in the furnace, 2 - transporting (free cooling), 3 - contacting with the punch, 4 - forming in the tools, 5 - 
cooling in the tools, 6 - out of die and cooling in the air. According to the variation tendency of temperature curve, the temperature Ac1 and Ac3 are about $776.8{ }^{\circ} \mathrm{C}$ and $824.4^{\circ} \mathrm{C}$ when B1500HS steel is heated in the furnace.

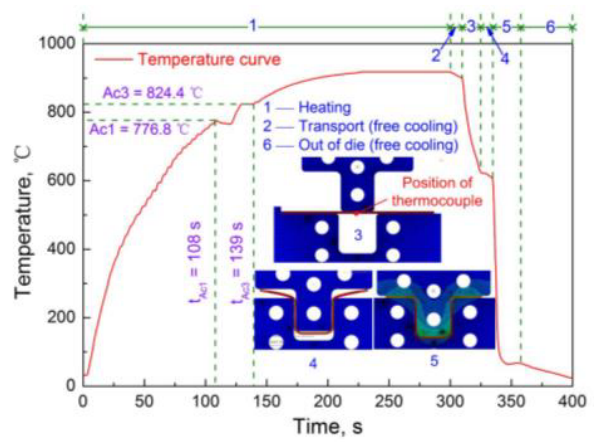

Figure 3. Temperature curve in the heating and cooling process

\subsection{Temperature of tools}

In the hot stamping, temperatures of four positions marked with symbol (1) (2) (3)and (4) shown in Figure 2 are measured by thermocouples. The temperature curves are shown in Figure 4.

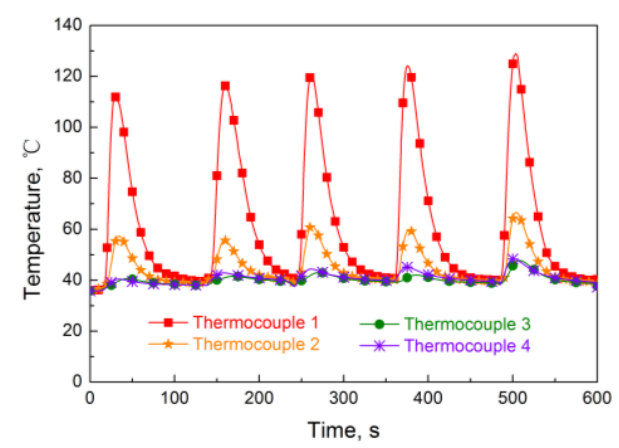

(a) $870^{\circ} \mathrm{C}$

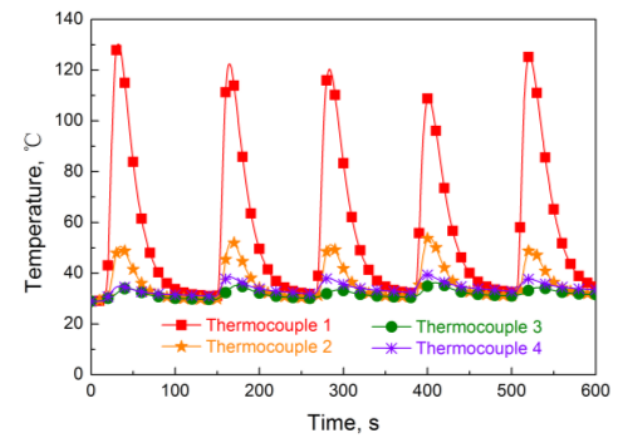

(b) $900^{\circ} \mathrm{C}$

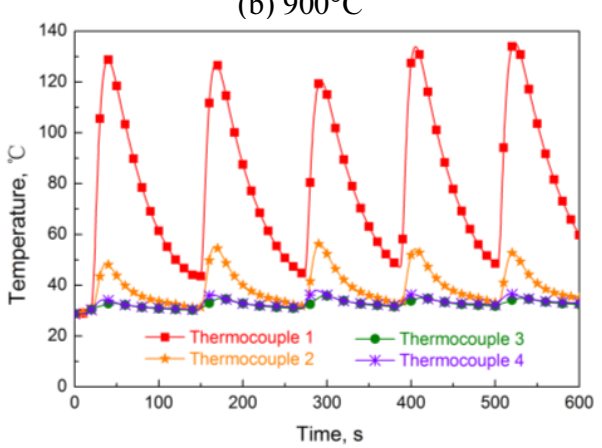

(c) $930^{\circ} \mathrm{C}$

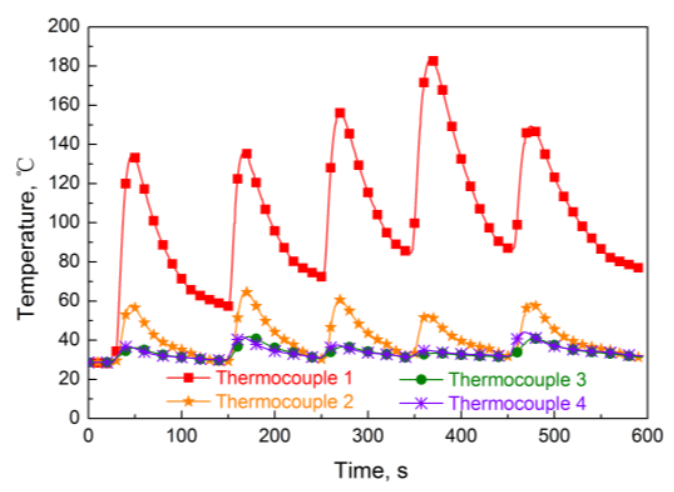

(d) $960^{\circ} \mathrm{C}$

Figure 4. Time-temperature curves measured by thermocouples

Before the punch contacts with the heated boron steel plate, the steel plate only contacts with the upper surface of die. Only a little heat energy transfers from the steel plate to the die, as the boundary heat transfer coefficient is smaller due to no pressure between them [20]. When the die contacts with the plate, the plate instantaneously separates from the upper surface of die due to the bending of steel plate, and begins deforming and sliding into the die with the punch, as shown in Figure 5. So the contact time is very short, and the temperature variation at the positions 4 is small, as shown in Figure 4.

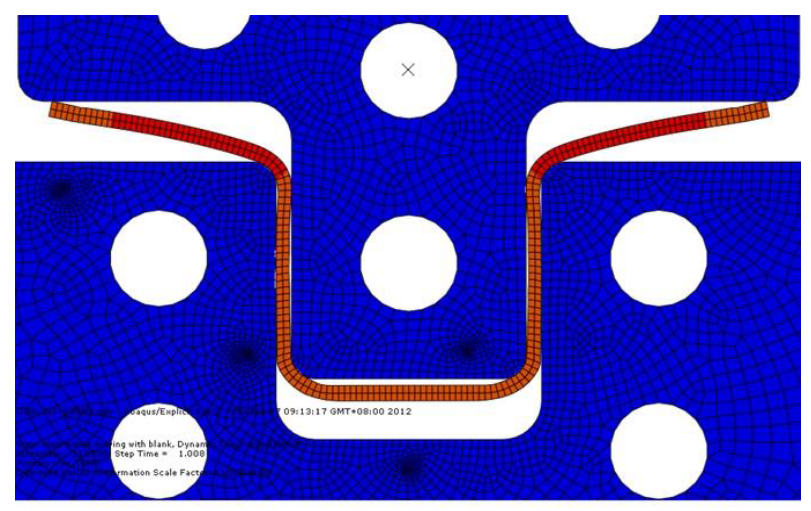

Figure 5. Hot stamping of steel plate simulated by FEM

When the steel plate completely contacts with the surface of punch and die, as shown in Figure 6, the pressure among them rapidly reaches to over $30 \mathrm{MPa}$. Much heat energy transfers from the steel plate to the die and punch, as the boundary heat transfer coefficient is relative to the pressure [21].

The temperature variation at the position (1) is significant, but the temperature variation at the position (2) is smaller than that at the position (1.) as shown in Figure 4. The main reason is that, the thickness of punch is small (about $24 \mathrm{~mm}$ ). Moreover, the volume of die is much larger than that of punch, so the temperature variation of the die is slower than that of the punch when the same heat energy is absorbed. 


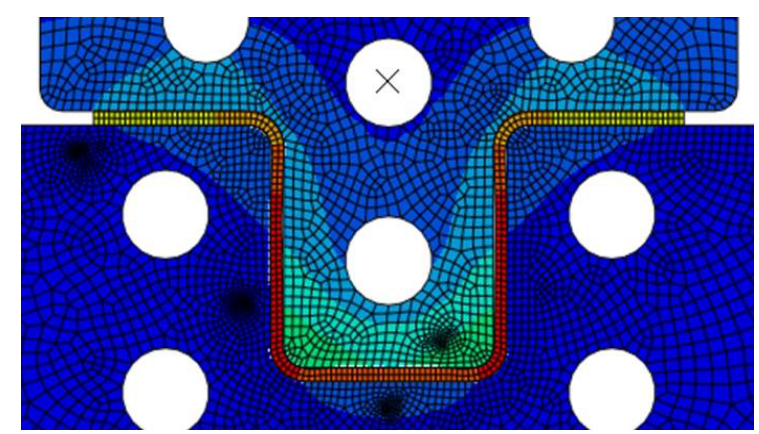

Figure 6. Diagram of stamped part completely contacting with punch and die

For the region II shown in Figure 1, it is in the gap of punch and die. Because the gap is a little larger than the thickness of plate, the clearance may appear among the punch, die and stamped part. The heat exchange between the forming part, punch and die is similar to the heat exchange without pressure. So the temperature variation at the position (3is smaller, as shown in Figure 4.

The temperature-time curves show that, with the increase of austenitization temperature, the temperature peak at the region (1)of punch increases, but there is a little effect on other regions of tools. After the die temperature increases to the peak, the heat energy taken away from the die and punch by the cooling water is more than that from the hot stamped part to the die and punch, so the temperatures of punch and die decrease with time.

The temperature variations of punch and die in Figure 4 show that, the temperatures of punch and die instantaneously rise and rapidly decrease under the action of the hot stamped part and tool cooling system, and the punch is easier to get higher temperature. The temperature of punch and die is one of the key factors to affect the microstructure and mechanical performance of forming part. If no cooling system works in the tools, the temperature of tools would become higher and higher. The microstructure and mechanical performance of hot stamped part would be affected. In addition, the service life of tools would be affected.

\subsection{Microstructure}

The samples are cut from the regions I, II and III of part shown in Figure 1 by WEDM. The samples are polished, and then etched using 4\% nitric acid alcohol solution. The microstructure observed by the optical microscope in the region I, II, and III is the lath martensite. The numerical simulation result of phase - transformation by finite element method shows the volume fraction of martensite is more than $98 \%$, as shown in Figure 7.

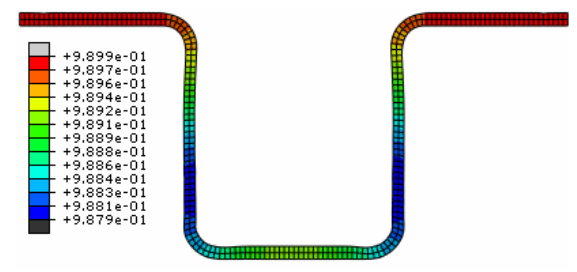

(a) $870^{\circ} \mathrm{C}$

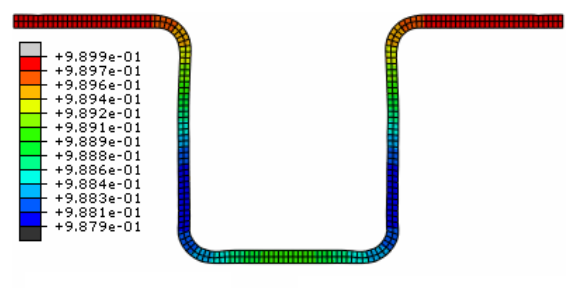

(b) $900^{\circ} \mathrm{C}$

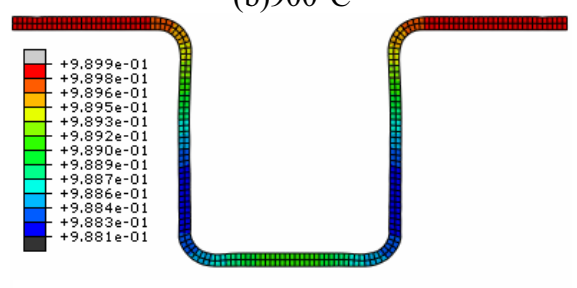

(c) $930^{\circ} \mathrm{C}$

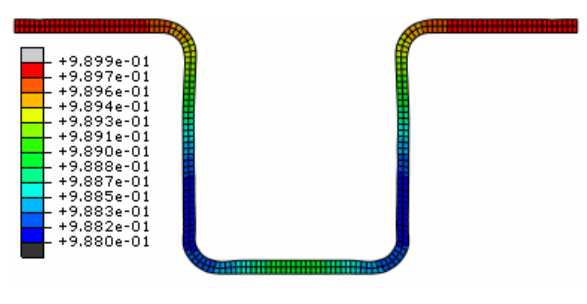

(d) $960^{\circ} \mathrm{C}$

Figure 7. Distribution and volume fraction of martensite

For the same hot stamped part, the microstructure in the region I, II, and III is very similar with each other, when the austenitization temperature is in the range of $870^{\circ} \mathrm{C}-960^{\circ} \mathrm{C}$. In the heating process, five steel plates are simultaneously put into the furnace for austenitization, their austenitization time are about $300 \mathrm{~s}$, $420 \mathrm{~s}, 540 \mathrm{~s}, 660 \mathrm{~s}$ and $780 \mathrm{~s}$. The results of microstructure show that, the austenitization temperature and time both have a significant effect on the size of martensite, the size of lath martensite becomes bigger and bigger with the increase of austenitization temperature and time, as the grain size of austenite is coarser and coarser with the increase of austenitization temperature and time. The microstructures relative to different austenitization temperature and time are shown in Fig. 8.

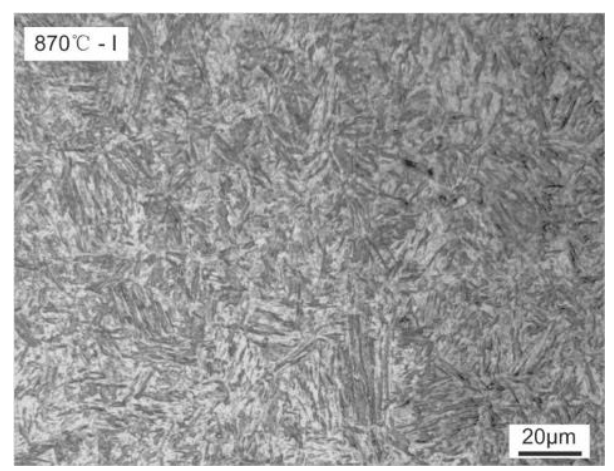



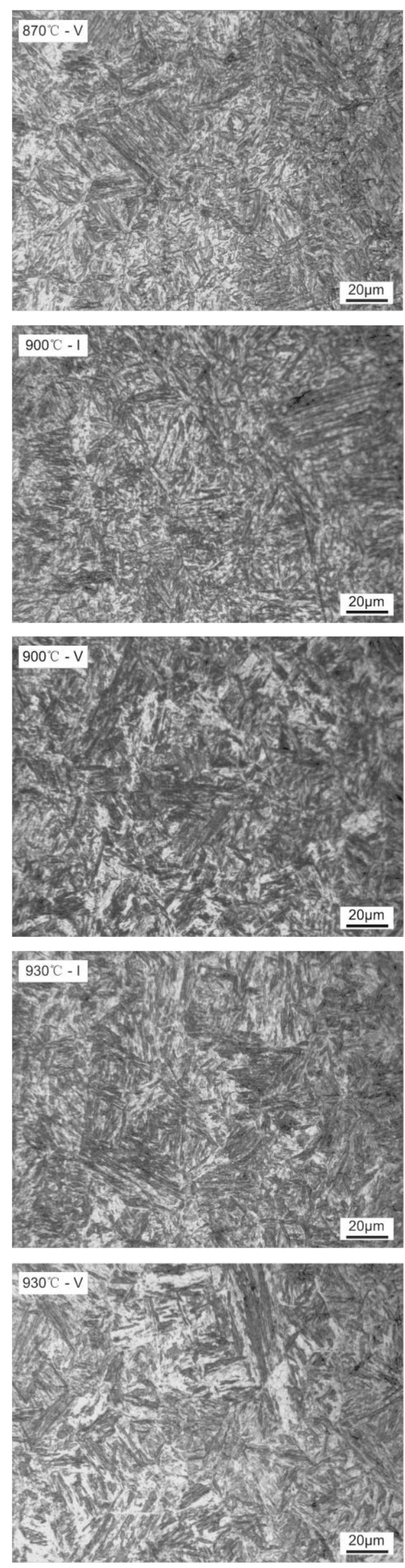
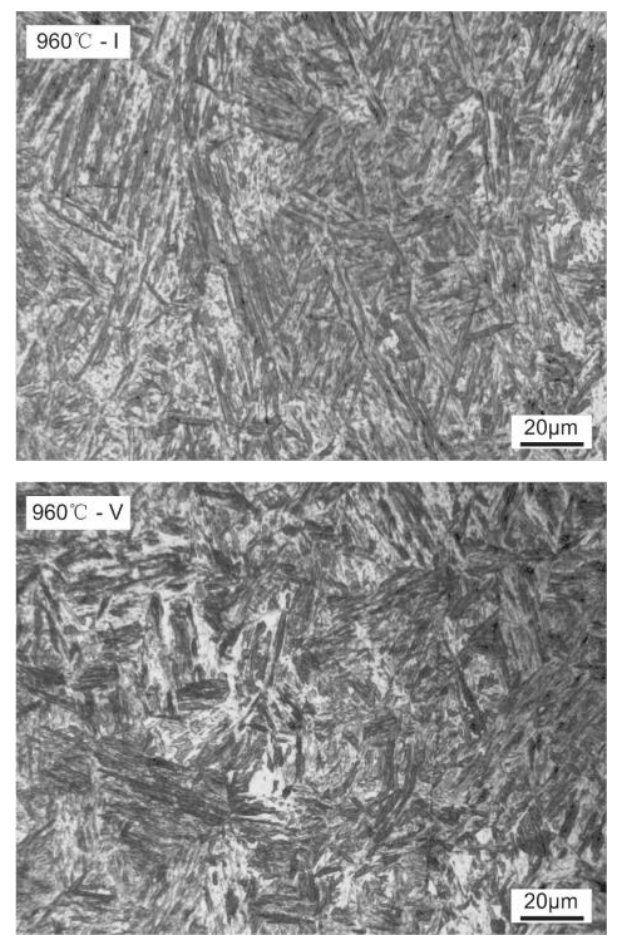

Figure 8. Microstructures relative to different austenitization temperature and time

\subsection{Hardness}

For the hot stamped parts at the different austenitization temperature, the averages of hardness tested by Rockwell hardness tester at the region I, II and III are shown in Table 2.

Table 2. Hardness of specimen in marked regions (HRC)

\begin{tabular}{|c|c|c|c|}
\hline & Region I & Region II & Region III \\
\hline $870^{\circ} \mathrm{C}$ & 43.8 & 42.7 & 44.1 \\
\hline $900^{\circ} \mathrm{C}$ & 45.5 & 42.8 & 43.5 \\
\hline $930^{\circ} \mathrm{C}$ & 45.7 & 44.4 & 45.4 \\
\hline $960^{\circ} \mathrm{C}$ & 45.3 & 43.7 & 44.7 \\
\hline
\end{tabular}

The testing result of hardness shows that, the austenitization temperature and time have a little effect on the hardness of samples, the values of hardness relative to the different regions and austenitization temperatures are very close. For the same part, the hardness at the region I and III is slightly higher than that at the region II due to the difference of cooling rate. In the hot stamping, the boundary heat transfer coefficient (BHTC) at the region I and III is larger than that at the region II due the higher pressure at the region I and III [22]. The heat flux from the part to the tools in the hot stamping can be described with Newton's law of cooling,

$$
q=H\left(T_{\mathrm{w}}-T_{\mathrm{c}}\right)
$$

Where, $q$ represents the heat flux, $H$ represents the BHTC, $T_{\mathrm{w}}$ represents the surface temperature of part, and $T_{\mathrm{c}}$ represents the temperature of tool.

According to Eq.(1), the heat flux $q$ will increase for fixed $T_{\mathrm{w}}$ and $T_{\mathrm{c}}$, if the BHTC rises. So the cooling rate at the region I and III is less than that at the region II. 
Hardness of steel is the function of the cooling rate at $700^{\circ} \mathrm{C}$ and chemical composition [23].

The hardness calculated by finite element method is shown in Table 2 and Figure 9. The calculation results show that, the hardness at the region I and III is slightly higher than that at the region II, which is basically consistent with the experiment results.

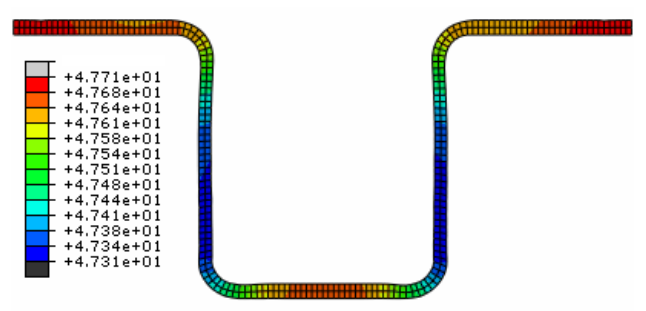

(a) $870^{\circ} \mathrm{C}$

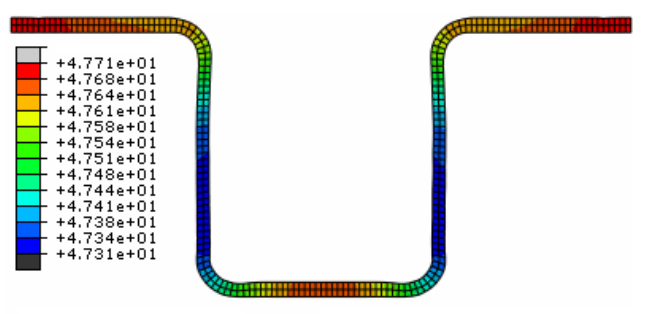

(b) $900^{\circ} \mathrm{C}$

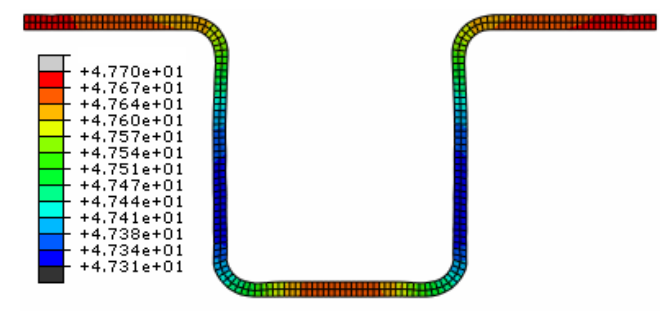

(c) $930^{\circ} \mathrm{C}$

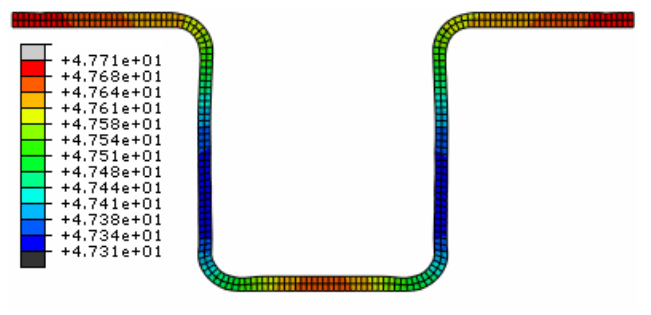

(d) $960^{\circ} \mathrm{C}$

Figure 9. Hardness distribution simulated by FE method

\subsection{Stress and strain}

The tensile samples are cut from the hot stamped part by WEDM, as shown in Figure 1. All the samples are done the static tensile test by CMT5000 tensile testing machine.

According to the definition, the true stress and true strain can be expressed as

$$
\sigma_{t}=\frac{F}{A_{1}}=\frac{F}{A_{0} l_{0}} l_{1}
$$

$$
\varepsilon_{t}=\ln \frac{l_{0}+\Delta l_{1}}{l_{0}}
$$

where, $\mathrm{F}$ is the instantaneous load, $\varepsilon_{t}$ is the true stress, $\sigma_{t}$ is the true strain, $A_{1}$ is the instantaneous section area of sample, $A_{0}$ is the original section area of sample, $l_{1}$ is the instantaneous length of sample, $l_{0}$ is the original gauge length of sample, and $\Delta l_{1}$ is the instantaneous variation of length in the tension testing.

The true stress and strain curves can be attained using the Eq.(1), Eq.(2) and the data measured by CMT5000, as the curves shown in Figure 10. The tensile strengths of at the region I, II and III are listed in table 3.

Table 3. Tensile strengths at the region I, II and III (Mpa)

\begin{tabular}{|c|c|c|c|}
\hline & Region I & Region II & Region III \\
\hline $870^{\circ} \mathrm{C}$ & 1806.3 & 1679.2 & 1758.6 \\
\hline $900^{\circ} \mathrm{C}$ & 1768 & 1651.8 & 1720.6 \\
\hline $930^{\circ} \mathrm{C}$ & 1771.3 & 1709.2 & 1724.6 \\
\hline $960^{\circ} \mathrm{C}$ & 1753.9 & 1714.1 & 1716.9 \\
\hline
\end{tabular}

The curves in Figure 10 and the data in Table 3 show that, the elongation and tensile strength of the sample at austenitization temperature $870^{\circ} \mathrm{C}$ is a little higher than that at other austenitization temperatures, as the grain size of austenite and size of lath martensite are finer, as shown in Figure 8.
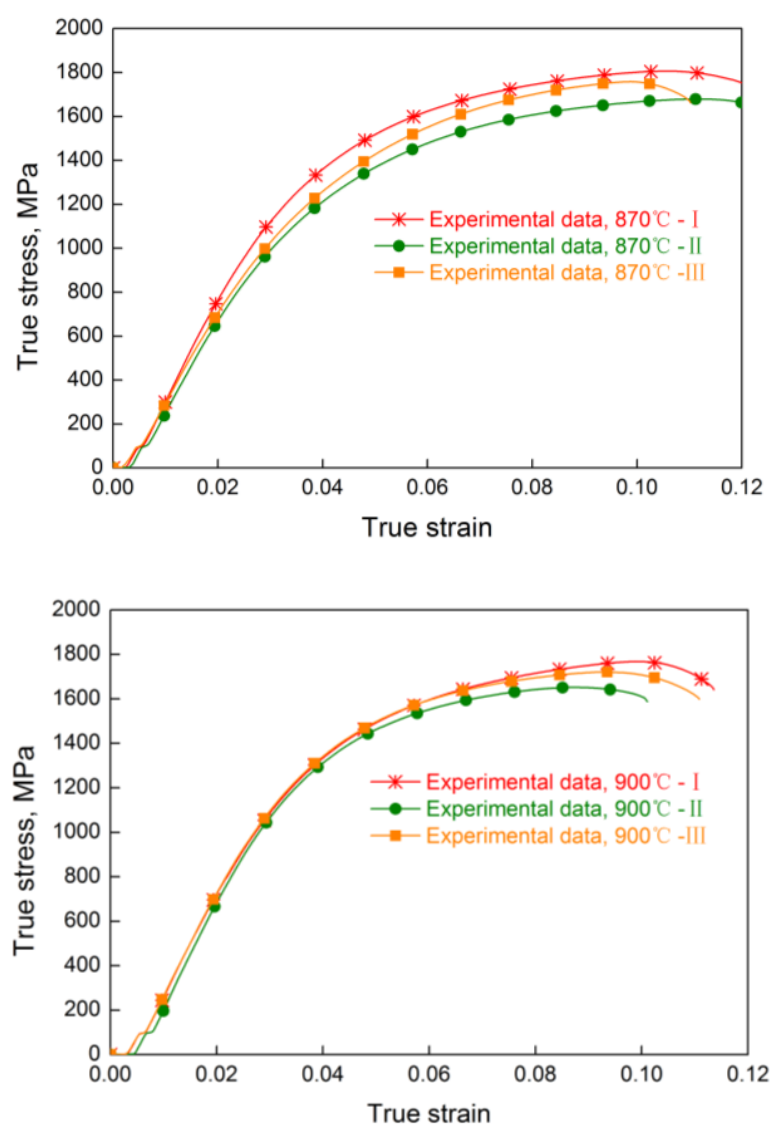

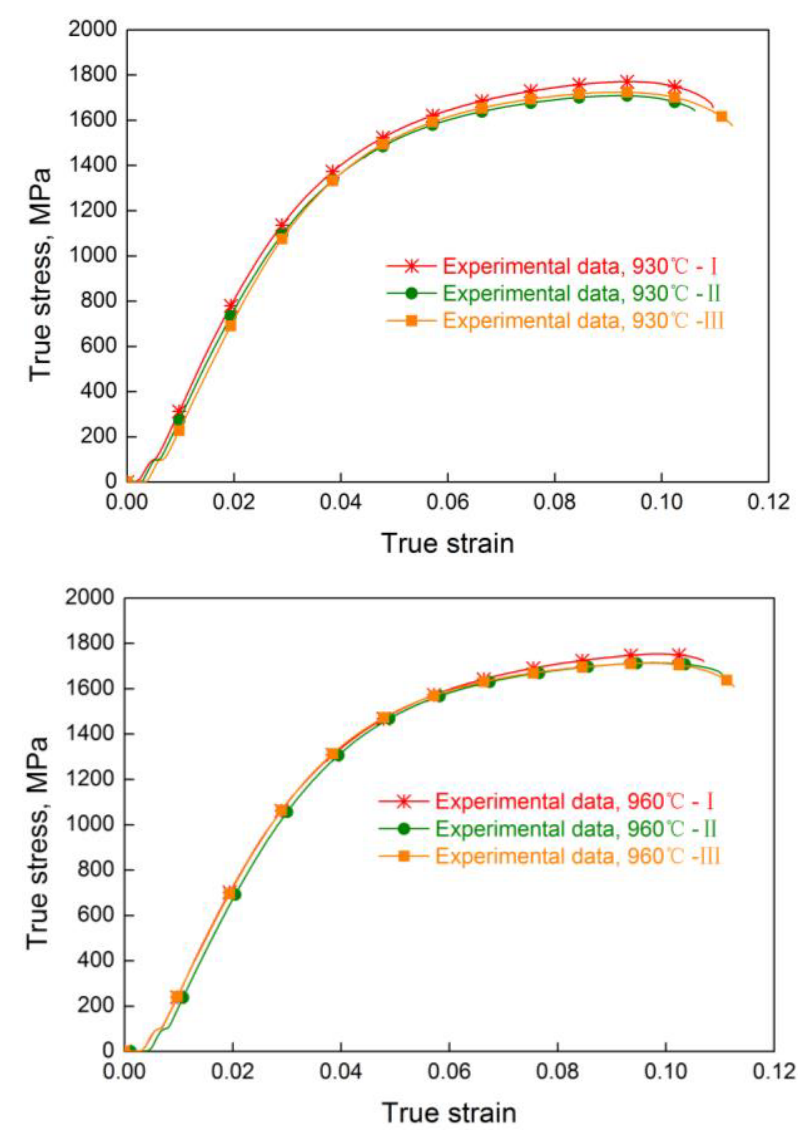

Figure 10. True strain-stress curves of sample at the region I,II and III

The tensile strength of the sample at the region II is a little less than that at the region I and III, as the cooling rate at region II is lower than that at other regions, and this is similar to the hardness distributions of hot stamped part. When the austenitization temperature of steel plate is $870^{\circ} \mathrm{C}$ or $900^{\circ} \mathrm{C}$, the difference of tensile strengths of sample at the region I, II and III is about $130 \mathrm{MPa}$. When the austenitization temperature of steel plate is $930^{\circ} \mathrm{C}$ or $960^{\circ} \mathrm{C}$, the tensile strengths at the region I, II and III are approximately same.

Except the part with the high and uniform strength, the hot stamping can also be used to manufacture the structural components with distributed properties. For instance, the crash performance of components like the B-pillar of car is improved when softer phases (e.g. ferrite or bainite) with lower strength but higher ductility are able to absorb a greater amount of energy during the crash [25].

The curves in Figure 10 and the data in Table 3 show that, the lower austenitization temperature is helpful for manufacturing the structural components with distributed properties by introducing a thin air gap between the tools and steel plate [26], or using the tool materials with the lower thermal conductivity [27], as the austenite attained at the lower austenitization temperature is particularly susceptible to the cooling rate [28].

\subsection{Fracture morphology}

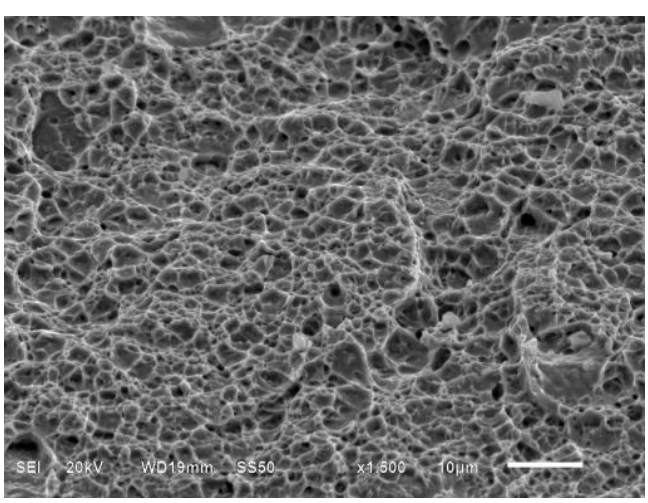

(a) $870^{\circ} \mathrm{C}$

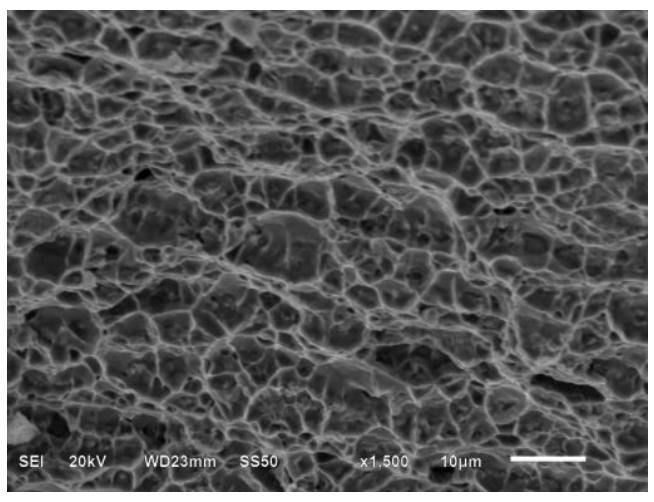

(b) $900^{\circ} \mathrm{C}$

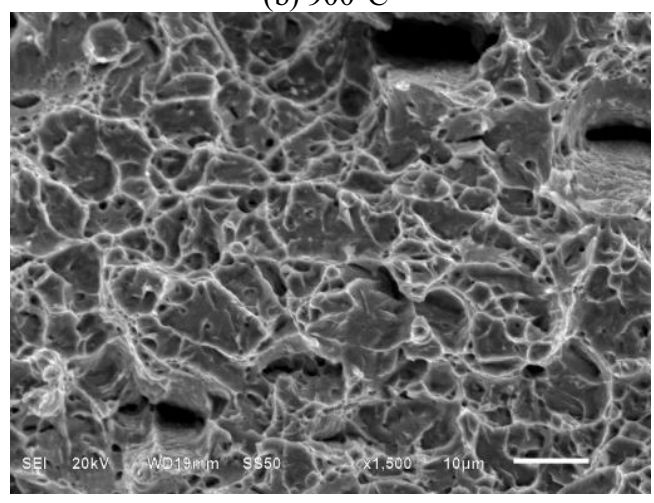

(c) $930^{\circ} \mathrm{C}$

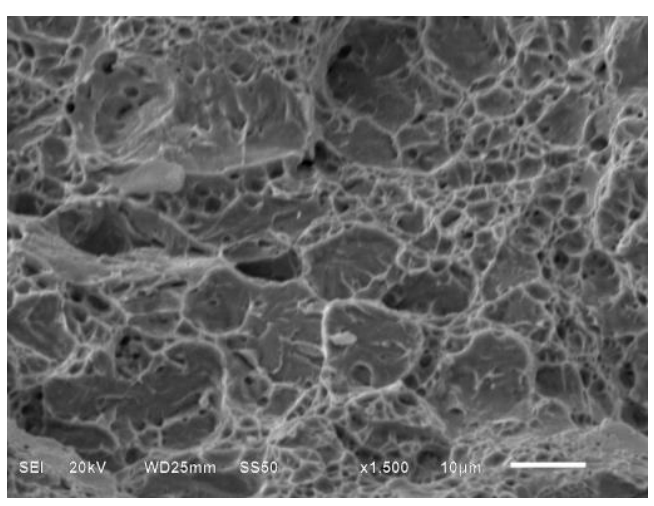

(d) $960^{\circ} \mathrm{C}$

Figure 11. Fracture morphologies at different austenitization temperature

The fracture morphology of sample austenitized at $870{ }^{\circ} \mathrm{C}, 900{ }^{\circ} \mathrm{C}, 930^{\circ} \mathrm{C}$ or $960^{\circ} \mathrm{C}$ is shown in Figure 11. 
All the fracture are the ductile fracture, the fracture of sample austenitized at $870{ }^{\circ} \mathrm{C}$ or $900{ }^{\circ} \mathrm{C}$ is the dimple, the fracture of sample austenitized at $930{ }^{\circ} \mathrm{C}$ or $960{ }^{\circ} \mathrm{C}$ is the mixture of quasicleavage and dimple, and the size of dimple rises with the increase of austenitization temperature.
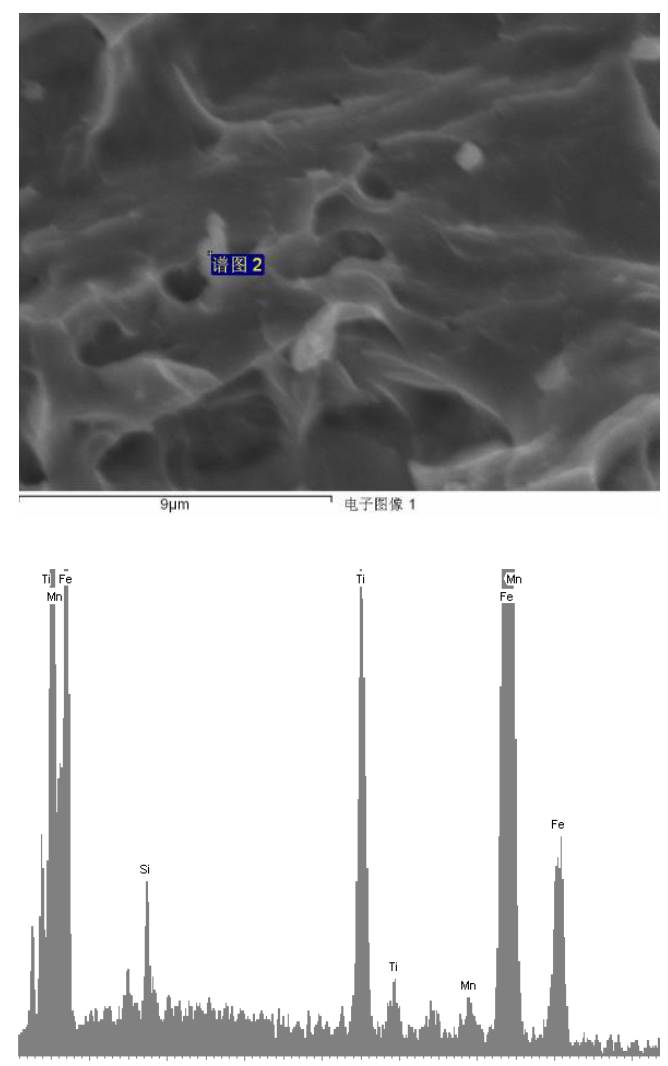

Figure 12. SEM / EDS analysis of fracture

According the temperature curve shown in Figure 3, pearlite and ferrite can fully transform into austenite when the austenitization temperature is over $824.4^{\circ} \mathrm{C}$. In the holding temperature process, the segregation of impurity elements (such as P, S, Si, Ti, etc) for B1500HS can occur on the grain boundary of austenite due to higher austenitization temperature, as shown in Figure 12. Some defect such as voids is easy to appear on the grain boundary due to segregation of impurity elements, and it can grow with the increase of austenitization temperature.

When the tension is put on the sample with the void defect, the voids can grow during deformation until they link together. Some continuous fracture paths may come into being, and some dimples can appear on the fracture of sample. The smaller dimple due to the fine grain size of austenite is helpful for the increase of tensile strength and elongation of sample. With the increase of austenitization temperature, the grain size of austenite and size of lath martensite become larger and larger, more and more quasicleavages occur on the fracture. All these are harmful to the tensile strength, can cause the tensile strength of the sample austenitized at $900{ }^{\circ} \mathrm{C}, 930$ ${ }^{\circ} \mathrm{C}$ or $960{ }^{\circ} \mathrm{C}$ is less than that at $870{ }^{\circ} \mathrm{C}$, as shown in Figure 8, Figure 10 and Figure 11.

\section{CONCLUSIONS}

The effect of austenitization temperature on the microstructure and mechanical properties of $\mathrm{B} 1500 \mathrm{HS}$ boron steel is studied by the experiment and finite element methods. The conclusions are as follows:

(1) The temperatures of punch and die rise due to the heated steel plate, and the punch is easier to get higher temperature than the die. Cooling system in the punch and die is very necessary for improving the microstructure and mechanical performance of hot stamped part.

(2) The austenitization temperature and time both have significant effects on the size of martensite, the size of lath martensite becomes bigger and bigger with the increase of austenitization temperature and time

(3) The austenitization temperature and time have not a distinct effect on the hardness of hot stamped part.

(4) The cooling rate has a significant effect on the tensile strength when the austenitization temperature is $870{ }^{\circ} \mathrm{C}$. The lower austenitization temperature is helpful for manufacturing the structural components with distributed properties.

(5) The fracture of hot stamped part austenitized at 870 ${ }^{\circ} \mathrm{C}$ or $900{ }^{\circ} \mathrm{C}$ is the dimple, the fracture of part austenitized at $930{ }^{\circ} \mathrm{C}$ or $960{ }^{\circ} \mathrm{C}$ is the mixture of quasicleavage and dimple, and the size of dimple rises with the increase of austenitization temperature.

\section{ACKNOWLEDGEMENTS}

This work was financially supported by the National Natural Science Foundation of China (51175302), the Program for New Century Excellent Talents in University (NCET-12-0342), The Science and Technology Development Program of Shandong and Huangdao (2014GGX103024, 20140132) and Scientific Research Foundation of Shandong University of Science and Technology for Recruited Talents (2013RCJJ002, 2013RCJJ005).

\section{References}

1. R. Kolleck, R. Veit, M. Merklein, et al. Cirp Ann.Manuf. Techn., 58, 275 (2009)

2. J.Y. Min, J.P. Lin, J.Y. Li, W.H. Bao. Comp. Mater. Sci., 49, 326 (2010)

3. M. Nikravesh, M. Naderi, G.H. Akbari. Mat. Sci. Eng. A, 540, 24 (2012)

4. H.P. Li, L.F. He, G.Q. Zhao, L. Zhang. Mat. Sci. Eng. A, 580, 330 (2013)

5. K. Mori, K. Akita, Y. Abe. Mach. Tool. Manu., 47, 321 (2007)

6. J. Yanagimoto, K. Oyamada. Cirp Ann.-Manuf. Techn., 56, 265 (2007)

7. S.H. Khan, M. Saeed Ahmed, F. Ali, et al. Eng. Fail. Anal., 16, 128 (2009)

8. Woo-Seung Lim, Hong-Seok Choi, Seok-young Ahn, et al. Int. J. Adv. Manuf. Tech., 70, 1189 (2014) 
9. Y. Xu, Z.D. Shan. Int. J. Adv. Manuf. Tech., 70, 257 (2014)

10. A.E. Tekkaya, H. Karbasian, W. Homberg, M. Kleiner. Prod. Eng. Res. Devel., 1, 85 (2007)

11. H. So, D. Fabann, H. Hoffmann, et al. J Mater. Process. Tech., 212, 437 (2012)

12. Z.W. Xing, J. Bao, Y.Y. Yang. Mat. Sci. Eng. A, 499, 28 (2009)

13. C.X. Lei, J.J. Cui, Z.W. Xing, et al. Physics Procedia, 25, 118 (2012)

14. J. Bao, Z.W. Xing, Y.Y. Yang, et al. Mater. Sci. Tech., 17, 326 (2009)

15. H.S.Liu, Z.W. Xing, J. Bao, et al. J. Mater. Eng. Perform., 19, 325 (2010)

16. H.S. Liu, W. Liu, J. Bao, et al. J. Mater. Eng. Perform., 20, 1 (2011)

17. H.H. Bok, M.G. Lee, H.D. Kim, et al. Metal. Mater. Int., 16, 185 (2010)

18. Y. Cai, W. Li, G. Li. Mater. Res. Innov., 18, 509 (2014)

19. L.F. He, H.P. Li, K. Gai, et al. Trans.Mater. Heat Treat., 36, 199 (2015)

20. B. Abdulhay, B. Bourouga, C. Dessain, et al. Heat Transfer Eng., 32, 497 (2011)

21. P. Hu, L. Ying, Y. Li, Z.W Liao. J Mater. Process. Tech., 213, 1475 (2013)

22. A. Azushima, K. Uda, H. Matsuda. J Mater. Process. Tech., 214, 3031 (2014)

23. P. Maynier, J. Dollet, P. Bastien. Hardenability concepts with applications to steel (AIME, New York, 1978)

24. H.P. Li, G.Q. Zhao, S.T. Niu, C.Z. Huang. Mat. Sci. Eng. A, 452-453, 705 (2007)

25. E.J.F.R. Caron, K.J. Daun, M.A. Wells. Metall. Mater. Trans. B, 44, 332 (2013)

26. H. Karbasian, A.E. Tekkaya. J Mater. Process. Tech., 210, 2103 (2010)

27. M. Maikranz-Valentin, U. Weidig, U. Schoof, et al. Steel Res. Int., 79, 92 (2008)

28. Q.Z. Gao, Y.C. Liu, X.J. Di, et al. Nuc. Eng. Des., 256, 148 (2013) 